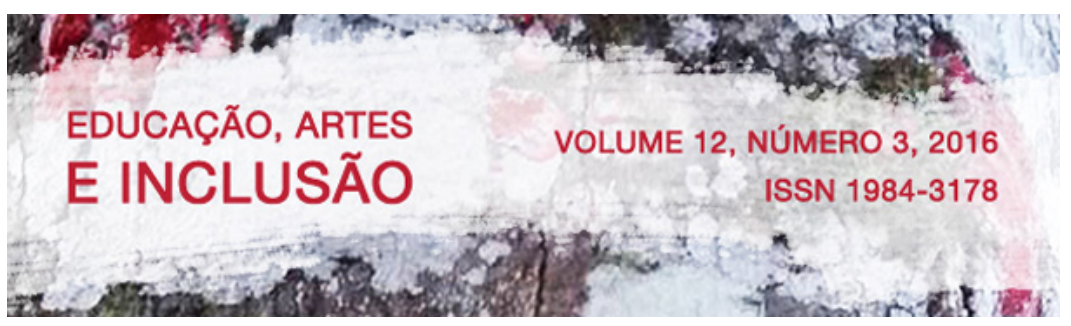

\title{
RELAÇÕES RACIAIS E EPISTEMICÍDIO: A ARTIMANHA POÉTICA \\ COMO POLÍTICA DE ENFRENTAMENTO AOS ATENTADOS AO \\ HORIZONTE SIMBÓLICO NEGRO NO BRASIL E NA ÁFRICA DO SUL
}

\author{
RACIAL RELATIONS AND EPISTEMICIDE: POETIC RUSE AS A COPING \\ POLICY AGAINST ATTACKS TO BLACK SYMBOLIC HORIZON IN \\ BRAZIL AND SOUTH AFRICA
}

DOI: http://dx.doi.org/10.5965/1984317812032016101

Elisabete Figueroa dos Santos, Bruno Vicente Lippe Pasquarelli - USC

\begin{abstract}
RESUMO
No bojo de tensões raciais extremas, como foram os casos da escravização racial no Brasil - e suas consequentes e atuais desigualdades - e do apartheid na África do Sul, vê-se florescerem movimentos de enfrentamento que solicitam como arma de atuação a poesia e os recitais/saraus. Neste contexto, por meio da poesia ecoam discursos e demandas por afirmação, bem como pela denúncia de disparidades. Logo, a partir do aporte das representações sociais e por meio de uma revisão de literatura, este trabalho busca, lançar luzes sobre as formas como a produção poética e as articulações dos coletivos de saraus foram e têm sido reivindicadas por movimentos históricos, no Brasil e na África do Sul, como estratégias para a articulação político-cultural, problematizando-se os quadros de subjugação da população negra. Conclui-se que as artimanhas poéticas intervêm no processo de construção de saberes por meio da edificação de um espaço em que os símbolos, as estéticas e o protagonismo negros são valorizados. Forjam-se referências artísticas, intelectuais e políticas orientadas para a contestação dos marcos de exclusão impostos às periferias e aos negros, bem como para a produção de discursos e representações de forma endógena.
\end{abstract}

PALAVRAS-CHAVES: Poesia, epistemicídio, recitais, desigualdades raciais, negros.

\begin{abstract}
On the extreme racial tensions, as were the cases of racial slavery in Brazil - and their consequent and current inequalities - and apartheid in South Africa, we hatch coping movements that request poetry and recitals/soirees as performance weapon. In this context, through poetry speeches and demands cry for affirmation, as well for denouncing disparities. Therefore, from the contribution of social representations and through a literature review, this work aims shed light on the ways in which the poetic production and the joints of the soirees' collectives were and have been claimed by historical movements in Brazil and South Africa, as strategies for political and cultural articulation, problematising the frames of subjugation of the Black population.It is concluded that the poetic ruses intervene in the knowledge construction process through the edification of a space in which the Black symbols, the aesthetic and the leadership are valued. Artistic,intellectual and political referencesare forged, oriented to challenge to the exclusion landmarks taxes to the peripheries and Black people, as well as to product discourses and representations endogenously.
\end{abstract}

KEYWORDS: Poetry, epistemicide, recitals, racial inequalities, black people. 


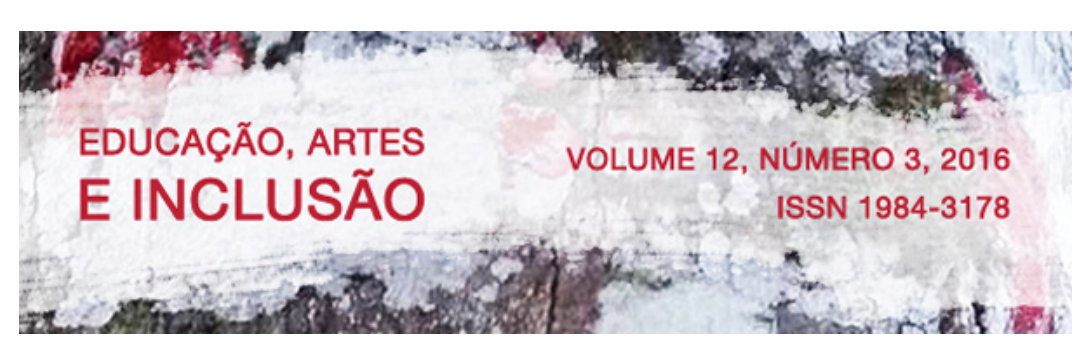

os movimentos de periferia e o avultamento que este tem alcançado nas últimas décadas. $\mathrm{O}$ rap, a literatura, os recitais poéticos, entre outros, aglutinando-se a uma marca identitária da periferia, irropem num debate também epistemológico questionando os formatos de produção de saber e os critérios secularmente utilizados para classificar os "intelectuais" e os "despossuídos de saber", a "cultura" e o "folclore", o "conhecimento" e a "informação corriqueira ou irrelevante" etc.

No bojo de tensões raciais extremas, como foram os casos da escravização racial no Brasil - e suas consequentes e atuais desigualdades - e do apartheid $^{l}$ na África do Sul, verifica-se o florescimento de movimentos de enfrentamento que solicitam como arma de atuação a poesia e os recitais/saraus. Neste contexto a poesia adquire significado político: através delas ecoam discursos e demandas por afirmação, bem como pela denúncia de disparidades. Por meio da problematização do cotidiano reivindica-se novos signos e significados.

Convém, portanto, destacar e colocar em questão as particularidades da poesia, em meio à dinâmica político-cultural forjada dentro dos marcos explicitados, e refletirmos sobre a capacidade de motivação do fazer poético enquanto revide e enquanto reinvenção (e quais os alcances e limites de ambas as possibilidades), assim como da organização dos recitais como arenas de debates e de mobilização de identidades e identificações.

A partir de reflexões realizadas como parte de uma pesquisa de doutorado, buscamos neste texto lançar luzes sobre as formas como a produção poética e as articulações dos coletivos de saraus foram e têm sido reivindicados por movimentos históricos como estratégias para a articulação político-cultural, problematizando-se os quadros de subjugação da população negra. Para tanto, utilizamos o respaldo da Teoria das Representações Sociais (TRS) (MOSCOVICI, 1978; JODELET, 2002; ARRUDA, 2002) para discutir o modo como tais movimentos inserem-se no debate acerca das relações étnico-raciais e produzem novas representações acerca dos lugares sociais destinados a brancos e negros. Assim, partimos do contexto das desigualdades étnico-raciais no Brasil e na África do Sul para discutirmos as

\footnotetext{
${ }^{1}$ Tratou-se de um regime social baseado na segregação racial. A partir deste sistema, brancos detinham direitos e privilégios que eram cercados a pessoas negras, como direito à participação na vida política, à escolha na zona de residência,
} 


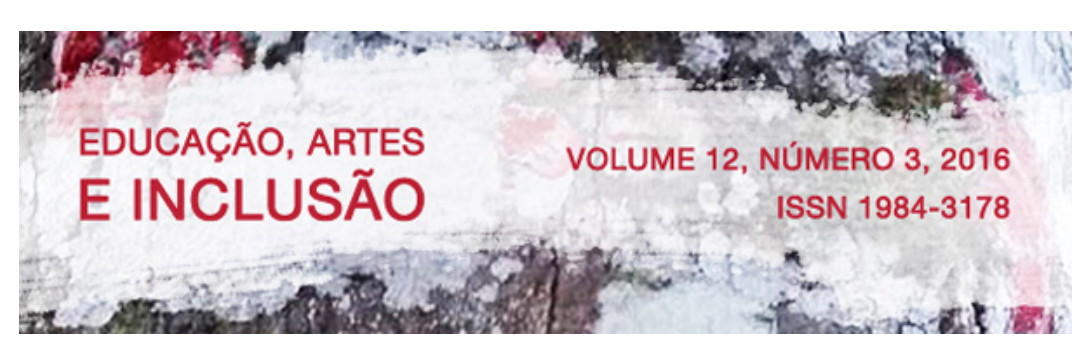

nuances dos processos de enfrentamento aos apagamentos e invisibilizações promovidos pelos movimentos poéticos, sobretudo em meio às táticas segregacionistas oficiais ou não.

Este artigo apresenta, portanto, reflexões teóricas realizadas a partir de levantamentos bibliográficos acerca dos movimentos de resistência aos regimes de segregação/escravização racial, respectivamente na África do Sul e no Brasil, que tiveram como estratégia de atuação a poesia e os recitais poéticos. Primeiramente, apresentamos e debatemos as noções de representações sociais, racismo e epistemicídio, tendo em vista salientar o contexto vigente nos períodos de explicitação das desigualdades étnico-raciais para produção e veiculação de conhecimentos e representações; e na sequência, sintetizamos algumas informações e reflexões sobre como os movimentos poéticos se articulavam/articulam no Brasil e na África do Sul.

\section{REPRESENTAÇÕES SOCIAIS, RACISMO E EPISTEMICÍDIO}

A propósito de discutir as distorções que ocorrem nas representações sociais, as quais são entendidas como formulações práticas, dadas no senso comum e construídas a partir da participação e pertencimento grupal (MOSCOVICI, 1978), propomos o resgate de um dito popular, bastante difundido no Brasil, o qual sugere que "quem conta um conto, aumenta um ponto". Ao anunciar um dado objeto, o sujeito informa a representação construída sobre o mesmo, bem como as mediações sociais às quais tal representação responde. Dessa forma, para evidenciar as possibilidades de distorções, cabe indicar que: quem conta um conto, aumenta, subtrai, transforma e/ou subverte um ou mais pontos. Isso implica em defendermos que a partir do lugar social que grupos e/ou sujeitos ocupam, o prisma pelo qual irão enxergar e atribuir significado a determinado objeto lhe é próprio e, portanto, à medida que se fala sobre dado objeto, fala-se de si e de sua apreensão sobre o objeto em questão, o que podemos chamar de representação social.

Torna-se explícito, assim, que a representação social é um modo de conhecimento sociocêntrico, que segue as necessidades, os interesses e desejos do grupo que a constroi, o que confere certa particularidade ao objeto em construção. Assim, quando percebemos esta espécie de "peculiaridade" na representação de certo objeto, significa que estamos diante da 


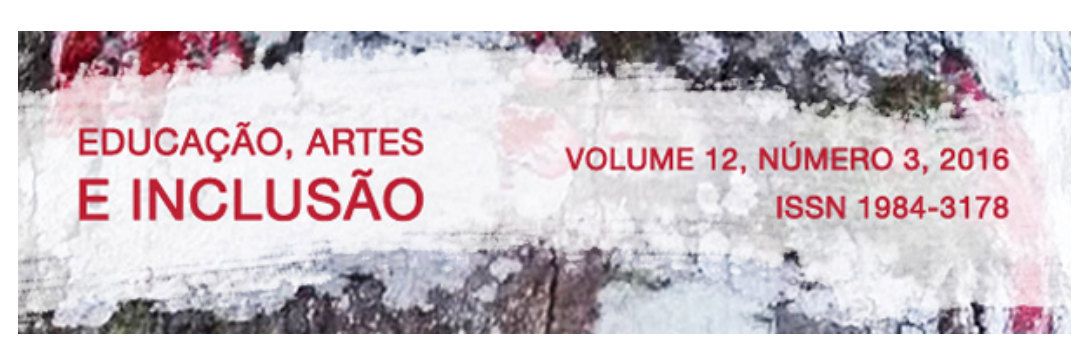

marca grupal/cultural impressa no processo de construção da representação (ARRUDA, 2002).

\begin{abstract}
O que aparece como uma distorção, modifica a organização ou o sentido do objeto para adaptá-lo aos desejos e necessidades de quem representa, como já explicava Festinger na dissonância cognitiva. A subtração de elementos, por sua vez, costuma ocorrer porque sua inclusão se torna difícil, por causa dos aspectos normativos ou valores de quem representa, como no caso da representação da psicanálise, que elimina a libido em virtude da sua associação com a sexualidade, ainda um tema difícil no momento da pesquisa. A suplementação é o acréscimo ao objeto representado de atributos ou conotações fornecidos pelo envolvimento ou imaginário do sujeito. Mas o que esta reflexão a respeito do estatuto epistemológico das representações aponta é, também, mais do que o tipo de "alteração" que a representação introduz com relação ao objeto, o interesse de observar como e por que acontecem essas modificações, o que elas indicam, e como elas constituem a representação, dando-lhe um sentido de verdade e uma eficácia simbólica (ARRUDA, 2002, p.139).
\end{abstract}

Tendo em vista desnudar o conjunto de componentes e relações contidos na representação social, entendida como saber prático, precisamos, a propósito de recomendações feitas por Jodelet (2002), responder a três perguntas fundamentais: Quem sabe e a partir de onde sabe? O que e como se sabe? Sobre o que se sabe, e com que efeito? Estas três perguntas revelam três planos, que ela sistematizou como: 1) as condições de produção e de circulação das representações sociais; 2) os processos e estados das representações sociais; e 3) o estatuto epistemológico dessas (ARRUDA, 2002). A partir dessas informações podemos entender o contexto de elaboração dessas representações e como este conhecimento produzido baliza as relações e os espaços em que se inserem o sujeito e o objeto da representação.

É necessário questionarmos, assim, por que nas discussões sobre as origens e formas de elaboração do saber, de forma geral e acerca das quais somos formalmente informados, prevalecem proposições que eliminaram do seu arcabouço de reflexões epistemológicas coerentes, não a mera interferência, mas a centralidade do contexto cultural e político para a produção, reprodução e contestação do conhecimento.

Santos (1996) aponta que as demarcações de territórios físicos e simbólicos foram propiciadas pela expansão europeia como responsáveis por excluir sujeitos e formas de conhecimento vinculadas aos sujeitos diferentes (aqueles que apresentavam modos de ser, 


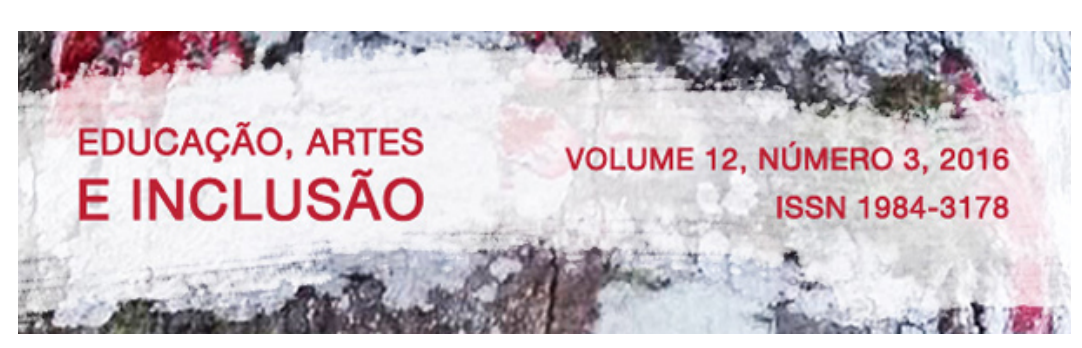

mundo cotidiano (FERREIRA, 2002). "Essas formas de conhecimento e representações também eram parte de uma totalidade articulada que eles possuíam" (ANDRÉ, 2007, p.160).

Contudo, a naturalização da desigualdade racial engendra no seio da sociedade resistências teóricas, ideológicas e políticas para se identificar o combate à desigualdade como prioridade das pautas políticas, acadêmicas e educacionais. Mais que isso, coloca barreiras e, no limite, impossibilidades de se pensar negro, ou de desvincular a representação que se tem sobre o negro da ideia de pobreza material, intelectual e cultural. Essas são perspectivas acessíveis a todos por meio da socialização e educação pautadas numa orientação eurocêntrica. De geração a geração tais crenças são ensinadas sem a necessidade de verbalizar a inferioridade ou a desconfiança nas capacidades dos negros. É algo que se dá no nível do não dito: nas posturas, preferências, defesas, piadas etc.

Conforme discutem clássicos estudos (SKIDMORE, 1976; HASENBALG, 1979; ANDREWS, 1998; GUIMARÃES, 1999; BENTO e CARONE, 2002; entre outros) em sociedades multirraciais e racistas como Brasil e África do Sul é possível notar a atuação do racismo na estruturação das desigualdades entre diferentes grupos étnico-raciais. Esse quadro resulta em possibilidades distintas para a construção dos sujeitos e suas subjetividades. A expressão dessas desigualdades pode ser identificada em todo o cenário social, do acesso à moradia às possibilidades de inserção e produção de conhecimentos nas universidades.

Segundo Guimarães (1999):

'Raça' é um conceito que não corresponde a nenhuma realidade natural.
Trata-se, ao contrário, de um conceito que se denota tão-somente uma
forma de classificação social, baseada numa atitude negativa frente a
certos grupos sociais, e informada por uma noção especifica de natureza,
como algo endodeterminado. A realidade das raças limita-se, portanto, ao
mundo social. Mas, por mais que nos repugne a empulhação que o
conceito de 'raça' permite - ou seja, fazer passar por realidade natural
preconceitos, interesses e valores sociais negativos e nefastos -, tal
conceito tem uma realidade social plena, e o combate ao comportamento
social que ele enseja é impossível de ser travado sem que se lhe
reconheça a realidade social que só o ato de nomear permite
(GUIMARÃES, 1999, p. 9).

Borges, Medeiros e d’Adesky (2002) defendem que o racismo é manifesto de por duas vias indissociáveis: a individual e a institucional. Em sua modalidade individual o 


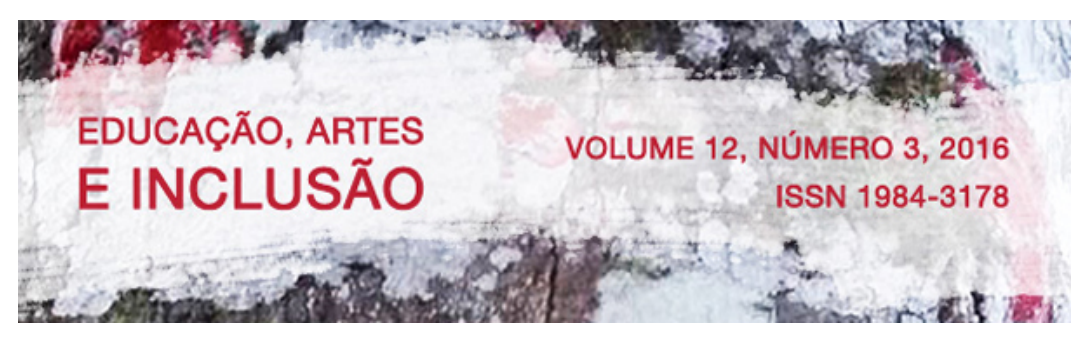

racismo é promovido por meio de atos discriminatórios um nível interpessoal, ou seja, cometidos por indivíduos contra outros indivíduos, podendo atingir níveis extremos de violência, como agressões, destruição de bens ou propriedades e assassinatos (GOMES, 2005). As experiências do extinto regime do apartheid na África do Sul e dos conflitos raciais nos Estados Unidos, sobretudo entre as décadas de 1960 e 1980 são exemplares históricos da expressão deste racismo. No Brasil, essa forma de racismo é também incidente, mas a própria sociedade e seus veículos de comunicação tendem a minimizar e/ou omitir tais manifestações. O racismo institucional, por sua vez, implica práticas discriminatórias sistemáticas fomentadas pelo Estado ou com o seu apoio indireto. Elas se manifestam sob a forma de isolamento dos negros em determinados bairros, escolas e empregos (BORGES; MEDEIROS; d`ADESKY, 2002; GOMES, 2005).

\section{Conforme salienta Jodelet (1998):}

Colocar em perspectiva a relação com o outro, a pertença social e sua tradução nas manifestações concretas da vida e da produção social abre caminho para a aproximação à alteridade radical. Esta última tem sua expressão ideal-típica e extrema no racismo - que convém considerar, como o faz Balibar (1988) como um "fenômeno total", evocando o "fato social total" de Mauss - na medida em que se inscreve ao mesmo tempo nas práticas e discursos, supõe representações, uma teoriazação e uma organização dos afetos. No quadro das práticas figuram as diferentes formas de violência, desprezo, intolerância, humilhação, exclusão, os discursos veiculam representações e teorias. As primeiras se caracterizam por serem elaborações intelectuais de um fantasma de profilaxia. Articuladas em torno das marcas da diferença, elas lembrariam a necessidade de purificar o corpo social, proteger a identidade de si e do nós de toda promiscuidade, de toda mestiçagem tidas como risco de invasão. Quanto às teorias - qualquer que seja sua origem - elas seriam "racionalizadas" por intelectuais. Essas representações e teorias organizam os afetos cuja forma obsessiva e irracional conduz à elaboração de estereótipos que definam tanto os alvos quanto os portadores do racismo. Tal combinação de práticas, discursos, representações, estereótipos afetivos vai explicar ao mesmo tempo a formação de uma "comunidade de racistas" entre os quais existem laços de imitação, e da pressão que leva as vítimas do racismo a se perceberem - por efeito do espelho - como comunidade. Aqui se poderia falar de "nós" secundários que vêm reforçar o jogo da identidade - nós primários do grupo que expressa o racismo (p. 58-59).

Tais representações prescritivas e normativas ficam de tal modo incrustadas nas relações e crenças desenvolvidas acerca dos negros que muitos destes acabam por negar seu 


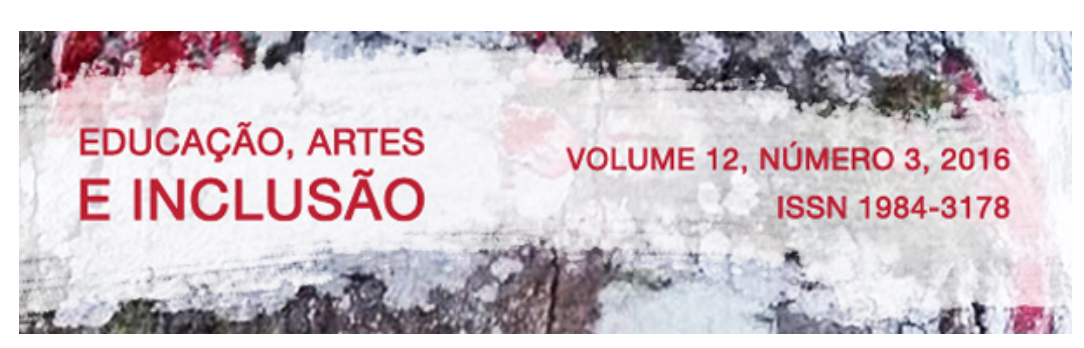

pertencimento, rechaçando práticas culturais de matriz africana. As representações sociais, que constroem e são construídas pelo senso comum, são, portanto, os óculos utilizados para captar o mundo e seus recortes; neste cenário, as identidades são o prisma a partir do qual posicionam-se esses mesmos óculos. As visões particulares resultantes deste arranjo podem ser estabelecidas como padrão social ou como perspectivas menores e sem relevância, a depender da posição ocupada pelo grupo que representa. Dessa forma, o racismo construiu e constroi uma zona muda das representações sociais que impede e/ou dificulta que negras e negros se apropriem de significados e práticas que remetam às culturas negras. Assim, as funções simbólicas do negro podem, sob dadas circunstâncias, serem forçadas a não representar a identidade de modo a aglutinar a ela signos negros. Neste contexto, o questionamento é imprescindível para recuperar a humanidade e o protagonismo dos sujeitos.

\section{BREVE CARACTERIZAÇÃO DOS EMBATES POÉTICOS ÀS DESIGUALDADES ÉTNICO-RACIAIS NO BRASIL E NA ÁFRICA DO SUL: ARTICULAÇÕES E NUANCES}

\subsection{As poesias e recitais na África do Sul}

$\mathrm{Na}$ África do Sul, a segregação racial teve início ainda no período colonial, mas o apartheid foi introduzido como política oficial após as eleições gerais de 1948. De acordo com o novo regime a população seria separada a partir de grupos raciais ("negros", "brancos", "de cor", e "indianos"), para os quais haveria políticas e direitos distintos. Havia, portanto, uma escala de cidadania.

Dessa forma, os negros foram radicalmente privados de sua cidadania, tornando-se legalmente cidadãos de uma das dez pátrias segregadas autônomas chamadas de bantustões. No entanto, na década de 1950 já se iniciavam lutas contra o apartheid. O Congresso Nacional Africano (CNA), liderado por Nelson Mandela foi o maior grupo oposicionista. Mas, com a prisão de Mandela em 1962, o grupo perdeu força e só se recuperou em 1990, com a saída de seu líder da prisão. Um plebiscito realizado em 1992 acabou com o apartheid e, em 1994, Mandela foi eleito presidente da África do Sul. Até hoje o país luta com as diferenças sociais impostas pela segregação racial (ALVES, 2006). 


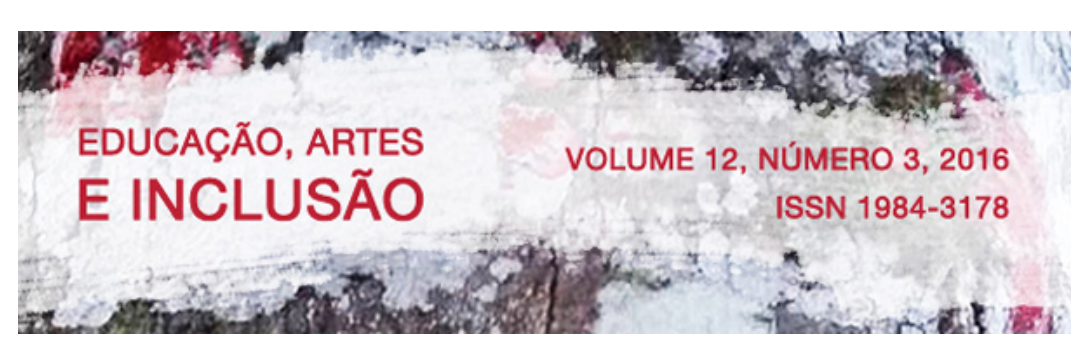

La identidad negra y el orgulho negro han sido introducidos en la lectura de poemas en las Iglesias y salones de Soweto. La mayor parte de la poesía que se lee no ha sido publicada. Está dirigida al público Negro, mostrando un énfasis fundamental en la participación del público. La participación está basada en el reconocimiento de unas experiencias comunes de sufrimiento e indignidad tanto por parte del poeta como del expectador. La representación, además, constituye un desafio de los Negros sudafricanos al rechazo de un status quo. El intercambio improvisado com el público es una parte integral de la representación llevada a cabo por el poeta (LARLHAM, 1985, p.19).

Larlham (1985) nos fala sobre o fervoroso movimento poético que teve como palco os salões e igrejas da cidade de Soweto, com poesias em grande medida dirigidas ao público negro. A atmosfera destes recitais primava pela partilha das experiências comuns de sofrimento entre poeta e plateia. As trocas com o público presente e as improvisações eram centrais para dar vida à performance poética.

Atualmente é possível verificar na África do Sul um movimento engendrado por meio dos recitais de poesia e de festivais poéticos. Neles, os "soldados da palavra" (termo utilizado pelo coletivo de poetas sul-africano Powertree ${ }^{2}$ para designar uma nova forma de poeta, mais vinculada às demandas das margens, os wordsouljahs [wordsoldiers]) são interlocutores que primam pelo questionamento, por deflagrar arranjos que subalternizam contingentes e/ou não contribuem para o bem estar e para a construção de políticas e ações voltadas para a promoção da igualdade. Nesta conjuntura, conhecimento é munição e a palavra é o artefato que dispara a reflexão e culmina na construção de estratégias de enfrentamento.

É interessante notar que este movimento é promovido por meio de recitais cujas poesias são recitadas em inglês, a despeito de haverem diversos idiomas locais relativos às diferentes etnias que compõem a população sul-africana. Além disso, os espaços em que acontecem os saraus são prevalentemente espaços centrais, de fácil acesso a pessoas vindas de distintas regiões das cidades e das cidadelas (townships), assim, esse movimento não acontece nas periferias ou margens geográficas, mas podemos lhe atribuir uma represetação periférica

\footnotetext{
${ }^{2}$ A designação "Powertree”faz sonoricamente alusão a "poetry” (poesia), tratando-se, no entanto, da conjugação de duas palavras em inglês "power" e "tree". Tal aglutinação faz referência aos Baobás, árvores comuns em África, cuja estrutura é monumental, suas raízes são profundas e, portanto, trata-se de uma árvore de grande resistência. Tais significados foram elucidados por Jacqui, poetisa que integra o respectivo coletivo, em entrevista durante visita técnica à África do Sul.
} 


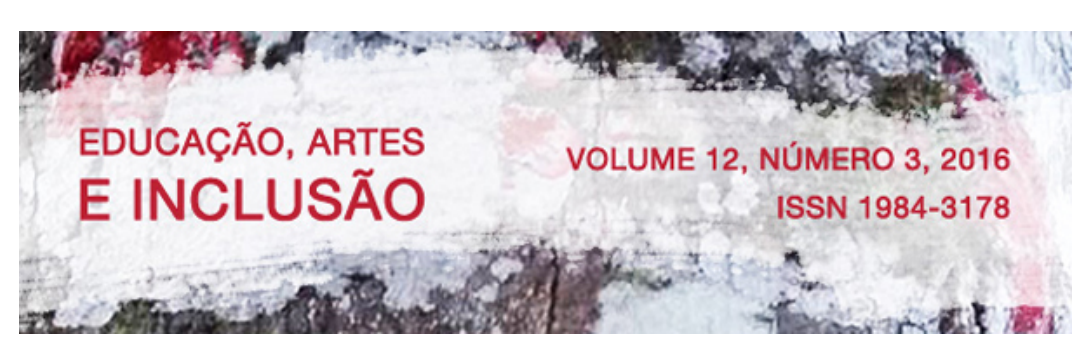

ao constatar a grande incidência da presença de pessoas, temas e debates negros e femininos em seus circuitos (SANTOS, 2015).

\subsection{Poesias e recitais periféricos no Brasil}

No Brasil, entre as décadas de 60 e 80 do século XIX, em plena vigência do regime escravocrata no Brasil, assistimos a um movimento de contestação à continuidade da apropriação do trabalho dos escravizados. Este empreendimento se deu a partir de várias províncias e contou com o engajamento de expoentes renomados, como Joaquim Nabuco, José do Patrocínio, Luís Gama, Manoel Querino, entre outros (MARINGONI, 2011; COTA, s/d; SANT’ANNA, 2006; PÍCOLI, 2009).

Com o reconhecimento oficial, em fins da década de 1860 e início da de 1870, de que a extinção da escravidão era apenas uma questão de forma e oportunidade, abriu-se um período que se caracterizou pela propaganda abolicionista propriamente dita (MARINGONI, 2011). Pelas vias desta campanha, associações foram compostas. Nestes espaços concorriam os membros da elite intelectual: redatores, poetas, professores, funcionários públicos e bacharéis (PÍCOLI, 2009). Estas associações e clubes tinham por propósito colocar nas agendas social e política o fim do trabalho escravo. Para tanto, privilegiaram como meios de comunicação os jornais criados também por meio deste movimento (COTA, s/d; SANT'ANNA, 2006; PÍCOLI, 2009). No rol de estratégias culturais utilizadas pelas associações estavam comícios, meetings, saraus etc.

Neste contexto, os saraus lítero-musicais eram o ambiente privilegiado para a difusão da campanha abolicionista, pois, enquanto eventos socialmente apreciados, as encenações e apresentações lítero-musicais atraíam o público com o qual se pretendia dialogar: membros das elites, senhores donos de escravos, intelectuais, acadêmicos, poetas e políticos brancos das classes altas. Ao negociar a abolição com este público, pretendia-se manter as rédeas do processo abolicionista sob a tutela do Estado e dos escravistas, conquistando-se adeptos da perspectiva abolicionista, bem como angariando-se donativos para a compra de alforrias. Nesta medida, valia-se de elementos reconhecidos e valorizados socialmente para a causa reformista. Negociava-se com os modos e valores vigentes para, de certa forma, contestar a 


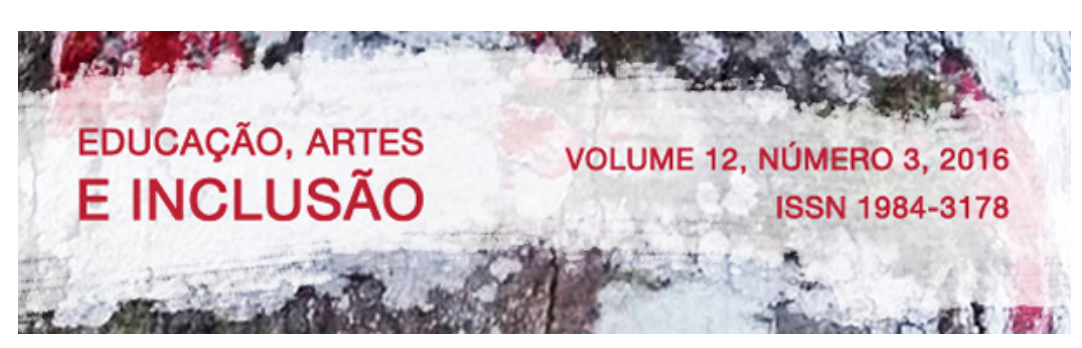

ordem posta, porém, sem deixar que esse movimento ganhasse força a partir dos desprestigiados da sociedade (os escravizados negros).

A subversão dessa barganha de negros e desprivilegiados da sociedade é evidenciada pelo movimento literário que tem origem justamente nas margens sociais. Nos saraus periféricos, que hoje eclodem em todo o Brasil e, sobretudo, nas periferias das grandes cidades, o negro é deslocado da posição de objeto para uma posição de sujeito, numa perspectiva mais ativa e comprometida (SANTOS, 2015).

Por meio deste agenciamento, os negros periféricos trazem para a página suas histórias, seus relatos, seus cotidianos de desigualdades e enfrentamentos, bem como seu anseio pela própria afirmação. Ao problematizar questões próprias às periferias, é bastante incidente o recurso às temáticas raciais. Dessa forma, os preconceitos, os escárnios, as lutas, vitórias e manifestações negras são postas em questão.

Segundo Silva (2010):

\begin{abstract}
A literatura opera como uma arma contra o esquecimento. No caso dessa nova configuração da ideia de marginalidade, a operação da memória coletiva, aliada a um espaço geográfico e a grupos sociais ocupantes desse espaço, trata da condição marginal como elemento identitário inalienável. A matéria prima literária e o que uniria esses escritores, portanto, estaria dada a partir de seu lugar de enunciação, do qual não poderia ou não deveria abrir mão (p.11).
\end{abstract}

Contexto de construção de novos significados para as identidades negras ${ }^{3}$ e marginais de contestação das formas de conhecimento do mundo e sobre o mundo difundidas como verdades universais, a literatura periférica tornou-se um veículo através do qual os negros e/ou periféricos trazem para a página suas histórias, seus relatos, seus cotidianos de desigualdades e enfrentamentos, bem como seu anseio pela própria afirmação.

A designação como literatura periférica, demarcando seu posicionando quanto a signos em questão e pontuando temas a eles pertinentes, de modo a desmistificar preconceitos

\footnotetext{
${ }^{3}$ O discurso sobre identidade negra só tem sentido num contexto plural no qual os distintos grupos raciais ocupam diferentes lugares na estrutura social. Assim, a identidade negra se refere à história comum que o olhar do mundo ocidental "branco" reuniu sob a denominação "negros", suas representações e significados atribuídos às possibilidades de ser e estar no mundo de sujeitos negros. Tais discursos e representações podem apreendidos e/ou ressignificados pelos próprios negros, dando forma às suas identidades (MUNANGA, 1988; 2012).
} 


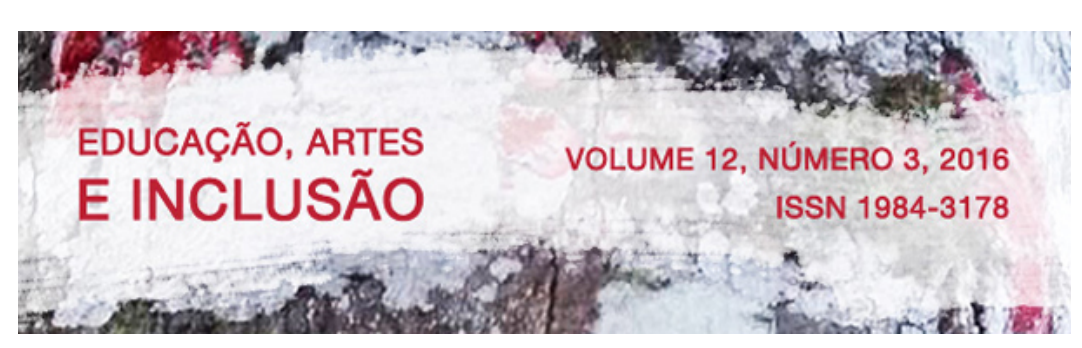

e tornar inteligíveis as capacidades, habilidades e anseios destes sujeitos de serem descolados de representações pejorativas, indicaria a necessidade de produzir-se enunciados para abalar o silenciamento e preencher o vácuo das dimensões da exclusão (NASCIMENTO, 2010; SILVA, 2011).

Neste âmbito, negro, marginal e periférico são termos que passaram a ser reivindicados por esta literatura constituindo, para os mesmos, significados e representações outros. Seu caráter de outridade, todavia, não se esgota na simplória designação como contraponto. É outro porque nas linhas tênues da ressignificação marca-se a autenticidade como local de enunciação, o comunitário como forma de registro e o protagonismo como estratégia. São sujeitos de seus próprios discursos e, portanto, pontuam o lugar de onde falam, como se pode observar neste excerto do Manifesto "A elite treme"^do Sarau Poesia na Brasa:

(...) agora é diferente, a periferia se arma de outra forma. Agora o armamento é o conhecimento, a munição é o livro e os disparos vêm das letras. Então, a gente quebra as muralhas do acesso e parte para o ataque. Invadimos as bibliotecas, as universidades, todos os espaços que conseguimos arrumar munição (informação). Os irmãos que foram se armar, já estão de volta preparando a transformação. Mas não queremos falar para os acadêmicos, mas sim para a dona Maria e o seu José, pois eles querem se informar. E a periferia dispara. Um, dois, três, quatro livros publicados. A elite treme. Agora favelado escreve livro, conta a história e a realidade da favela que a elite nunca soube, ou nunca quis contar direito. Os exércitos de sedentos por conhecimento estão espalhados dentro dos centros culturais e bibliotecas da periferia. A elite treme. Agora não vai mais poder falar o que quiser no jornal ou na novela, porque os periféricos vão questionar. $\mathrm{O}$ conhecimento trouxe a reflexão e a reflexão trouxe a ação, e agora a revolta está preparada, e a elite treme. Não queremos mais seu tênis, seus celulares. Não queremos mais ser mão de obra barata, e nem consumidores que não questionam a propaganda. Queremos conhecimento e transformações nas relações sociais. A elite treme. Agora não mais enquadramos madames no farol, e sim queremos ter os mesmos direitos das madames. E é por isso que a elite TEME.

Como se pode perceber, num primeiro momento explicita-se a representação de periferia que comumente figura no imaginário social como território da violência, da escassez, da falta, para, posteriormente, introduzir um complemento a esta noção de periferia: a

\footnotetext{
${ }^{4}$ Disponível em < brasasarau.blogspot.com> $>$ acessado em Agosto de 2013.
} 


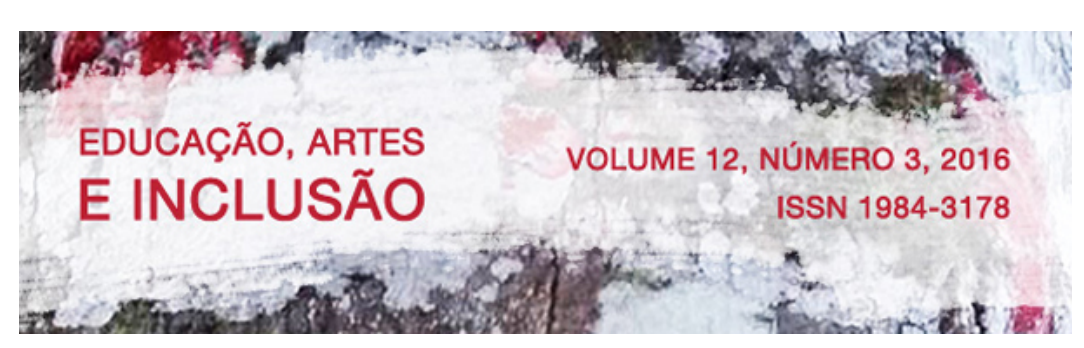

periferia do conhecimento. A ideia de margem, enquanto lugar da exclusão, não se restringe aos locais de escassez de serviços e condições subalternas de vivências, mas avançam e convergem para a apartação dos sujeitos marginais dos domínios do conhecimento. Neste cenário, letra é disparo, livro é munição e conhecimento é arma! Compõe-se a arena.

Está posta a negativa em assumir o lugar histórica e socialmente desenhado para estes sujeitos. Questiona-se, portanto, a capacidade dos intelectuais de elite de analisarem de forma imparcial as relações periféricas e, no limite, coloca-se em causa a própria noção de neutralidade tão valorizada por algumas Ciências. Estes sujeitos gritam: Não aceitamos este lugar! E, apontam as posições que assumem e valorizam: “...favelado escreve livro...” e “...conta sua história...".

Diante das engenhosas estratégias desembainhadas pelos grupos dominantes para manterem os periféricos à parte da possibilidade de produção de conhecimento, os "favelados" questionam a restrição de acesso aos "templos do conhecimento" (universidades e bibliotecas) e lançam suas táticas de enfrentamento: "Então a gente quebra as muralhas do acesso e parte para o ataque". Os centros comunitários e bibliotecas (dentro destes, os próprios bares onde ocorrem os saraus e nos quais, inclusive, improvisam-se bibliotecas) das periferias têm seus bancos ocupados como ponto de fortalecimento. O "exército" adentra os locais de produção de conhecimento e em posse de informações, passa a questionar, apontar os vieses e propor outras formas de conhecimento. Ao voltarem para suas comunidades orquestram ações, debates e vivências pautadas num teor de questionamento das tendências de naturalização de lugares, desigualdades e representações sociais (SANTOS, 2015).

É primordial dar ênfase ao ato de apropriação do direito de falar em primeira pessoa e, mais que isso, de questionar e denunciar a contradição e os equívocos. O direito de produzir narrativas em primeira pessoa, contudo, não esgota suas demandas. Pelo contrário, é local de passagem para denunciar as falácias, anunciar suas visões de mundo e, sobretudo, reivindicar seu direito de ser sujeito em primeira pessoa, isto é, de localizar-se, tecer escolhas e posicionar-se à medida que se apresenta e fala de si.

Nesta conjuntura, o conhecimento é o artefato que dispara a reflexão e culmina na construção de estratégias de enfrentamento ("revolta"). 


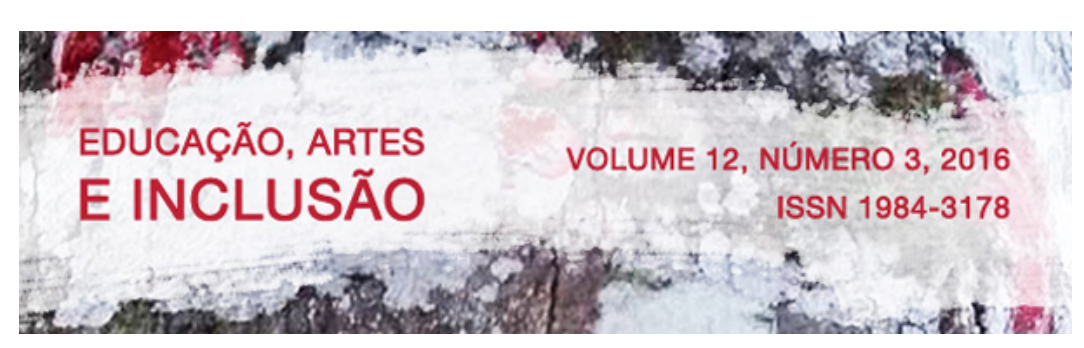

Desta forma, percebe-se haver um trânsito entre o político e o cultural: marca que se faz presente nas manifestações negras. Por meio das manifestações negras constroem-se políticas e questionam-se lugares sociais. Em alguma medida, os saraus ou recitais têm desempenhado este papel por meio da artimanha poética de enfrentamento (SANTOS, 2015).

O movimento de saraus se constroi enquanto produção pelas vias da cultura. Sobressaem-se manifestações e discursos culturais revestidos pelas marcas da diferença. Sobretudo das diferenças que são causa para o cerceamento de direitos e práticas discriminatórias. Negros, pobres, mulheres, entidades e movimentos sociais diversos, abundantes nos bairros periféricos e portadores de identidades atreladas a signos pejorativos, inserem-se em tais articulações e utilizam o fazer poético e o open mic para nomearem as particularidades que atravessam suas trajetórias e os convocam a responderem por tal inscrição, assim como para compartilharem narrativas que elucidam o ponto a partir do qual se emite afirmações e propostas de esquivas estratégicas.

As marcas da subalternidade estão presentes nas sessões poéticas seja como motes ou fisicamente, sendo anunciadas e debatidas. As relações de raça e gênero amplamente praticadas são denunciadas como desencadeadoras de tensões e sofrimento psíquico de acordo com os discursos e representações difundidos e incutidos socialmente. O não silenciamento acerca de temas tão latentes no cotidiano destes sujeitos, mas silenciadas em diversos outros espaços, indica um diferencial em seu tratamento pelo viés artístico, de modo a construir-se um espaço de sensibilização e politização. Neste ambiente, não apenas se problematiza a impressão negativa destas marcas, mas propõe-se outras demarcações para identidades e modos de ser.

\section{CONSIDERAÇÕES FINAIS: DESCOLONIZANDO SABERES}

Entendemos que a capacidade de questionar, apontar equívocos e desenvolver novas presunções, hipóteses e teorias está intimamente relacionada à possibilidade de superação de máximas consideradas universalmente aplicáveis e, logo, à eclosão de novas formas de conhecimento. A desnaturalização é uma forma de politização e só pode ser alcançada através do questionamento dos vieses que compõem os discursos e representações. 


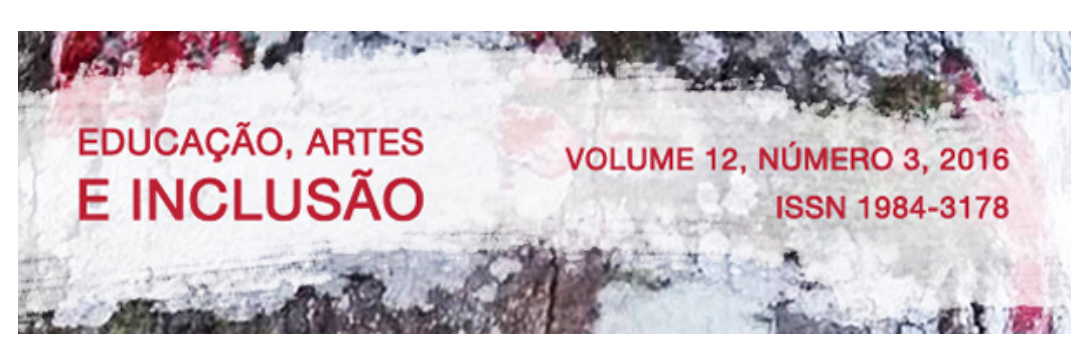

Ainda que discursos convoquem determinados sujeitos à assunção de certas identidades e posições-de-sujeito, estes indivíduos podem tecer formas de subverter tais convocações por meio da construção de estratégias de resistência e mesmo de desmarcação, o que levaria à produção de outras e novas formas de saber e de novos discursos.

De acordo com Deschamps e Moliner (2009):

\begin{abstract}
A "ameaça à identidade" é antes de tudo considerada como decorrente da inferioridade de um agente social numa dada situação. Os agentes sociais que tomam a iniciativa da diferenciação, da inovação, seriam aqueles que são negados por aqueles que lhe são superiores, aqueles que ocupam uma posição irremediavelmente inferior nas dimensões da comparação. Esta posição numa escala social colocaria em questão sua identidade e induziria, por isso mesmo, tentativas de "desmarcar-se" daqueles aos quais se comparam, de criar novos critérios de comparação em função dos quais eles são diferentes e, deste modo, tornam-se incomparáveis e escapam de sua inferioridade (p.43).
\end{abstract}

Diante de formulações e políticas que não entendiam negros e pobres como sujeitos de conhecimento (portadores do direito a acessar as distintas esferas e formas de informação e contribuir para a construção de novas formas de saber), as margens foram justamente a ocasião para dar vida a intelectuais representantes dos indesejados como sujeitos de saber (mas, bem-quistos como objetos) (SILVA, 2011; NASCIMENTO, 2010; SILVA, 2012).

Silva (2012), em contribuição à problematização da figura do intelectual - a qual, segundo o autor, entrou em colapso a partir da década de 1970 - enquanto sábio detentor da capacidade de professar análises universalizantes e pretensiosamente neutras acerca do mundo e das relações que nele se constroem, afirma que a periferia tem forjado seus próprios intelectuais. $\mathrm{O}$ autor explica que estes intelectuais, a partir de sua inserção social, encarnam os dramas cotidianos, problematizam as ambiguidades que pairam na vivência nas margens e, assim, representam a voz da massa periférica.

Reiteramos as conclusões de Silva (2012) propondo que as artimanhas poéticas propostas pelos recitais identificados nas periferias brasileiras e também aqueles organizados pelos coletivos sul-africanos tornaram-se palcos para a alfabetização e politização (aproximando-se das orientações de Martin-Baró (1996)) e para a formação de poetas, ativistas, escritores e intelectuais outros. 


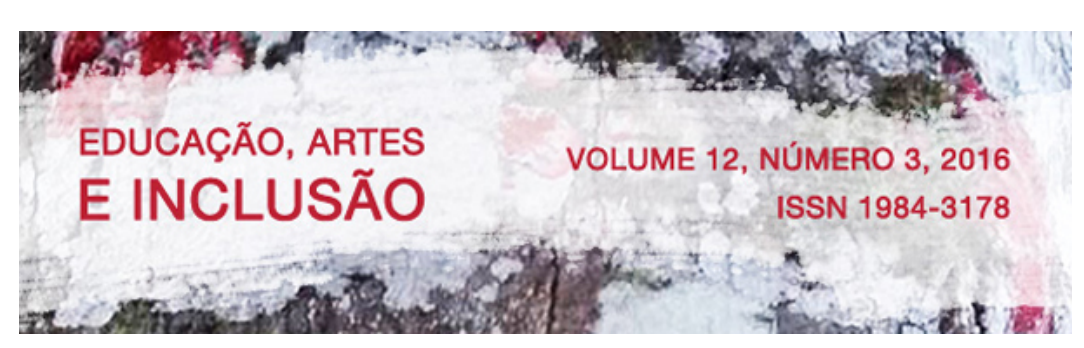

Retomamos a proposição feita pela Teoria das Representações de que à medida que nós representamos as coisas, nós nos representamos nelas. Não se trata da representação enquanto evento perceptivo que apreende parte de uma realidade exterior, mas enquanto processo pelo qual edificamos a realidade. É pelo processo de representação que transformamos algo não-familiar - sem sentido, carente de significado - em algo dizível e legível, portanto, inteligível. No entanto, esta realidade apresenta traços das identidades que compõem os sujeitos que representam, ao passo que as identidades daqueles que representam incorporam traços do objeto representado (MOSCOVICI, 1978; JODELET, 2002; ARRUDA, 2002).

É neste sentido que Munanga (1988), tendo em vista desvelar os significados que conduziram à edificação da diferença racial como alteridade, propõe que a invenção do negro - enquanto sujeito subalterno, próprio para trabalhos desqualificantes, ser sem alma, subhumano etc. - foi elaborada no seio da ordem colonial e escravocrata. Não obstante, muitas vertentes do Movimento Negro buscam na África pré-colonial elementos aos quais aglutinarem suas identificações. Num contexto social e político cuja contenda por direitos de igualdade transforma a diferença racial em causa para a objetificação e inferiorização, o recurso à ancestralidade africana e sua cosmovisão diversa emerge como tática para reorientar subjetividades e identidades, para rechaçar o posto de objeto e constituir-se sujeito. Exemplos destes empreendimentos são notáveis nos contemporâneos recitais periféricos que trazem à cena os tambores e seus toques; o berimbau; a valorização de estéticas afrobrasileiras; elementos das menifestações e religiosidades de matriz africana etc. (SANTOS, 2015).

Estes movimentos poéticos colocam no centro da discussão a necessidade de desnaturalizar a hierarquia existente entre sujeitos, a partir das inscrições raciais, de classe, gênero etc. e suas respectivas formas de saber. Como bem coloca a Teoria das Representações Sociais (TRS), o saber de senso comum apresenta racionalidade e edifica relações, compõe práticas e conduz os sujeitos a questionarem as fendas do social (MOSCOVICI, 1978; JODELET, 2002).

Logo, por meio da artimanha poética dá-se a conhecer a perspectiva de quem a produz. Não de forma solipsista, mas como resultante dos processos representacionais que compõem e atravessam os sujeitos e suas identidades e, portanto, expressam-se em suas textualidades e versações. Dominar os meios e modos de produção de literatura, portanto, configura uma 


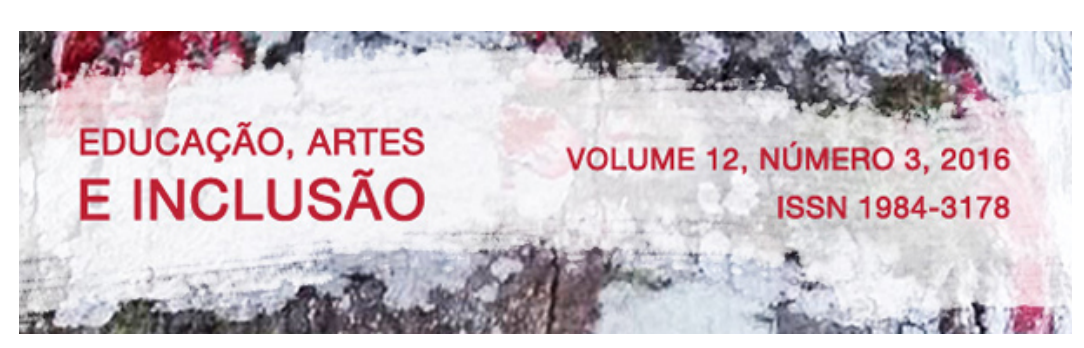

engenhosa estratégia para os sujeitos que são construídos a partir de estereótipos e representações sociais prescritivas. A poesia funciona como veículo para se desvelar tópicos e elementos suprimidos; para salientar outros sentidos cabíveis a objetos cujos significados atribuídos sejam negativos e; para posicionar-se como produtor de conhecimento, uma vez que tradicionalmente as letras e os versos têm sido ferramentas de acesso privilegiado para uma elite branca, o que fez com que as margens integrassem essa produção quase que exclusivamente como mote e por meio de distorções.

Edificar-se sob os marcos da marginalidade, constituir e ser constituído pelos pontos de cisão de discursos e representações sociais, são causas para esforços contínuos de familiarização e de posicionamentos identitários. Dessa mobilização resultam significados socialmente orientados. Isto é, à medida que se aponta que a elaboração de representações está vinculada aos grupos que as compõe e às suas identidades, propomos, de um lado, que o processo de atribuição de significado está fortemente vinculado aos respectivos grupos de referência, por outro, propomos que os significados não são nem tão estáticos, tampouco, universais, como já se propôs em alguns momentos na história das Ciências Sociais de maneira geral. A discussão política sobre as desigualdades e, mais especificamente, a abordagem da dinâmica racial, gera conteúdos que desestabilizam o sistema representacional. Estes novos discursos deslocam elementos que compõem as representações sociais existentes e provocam a emergência de elementos substitutivos: as representações se reciclam e se deslocam, dando origem a outras representações.

Cabe, por fim, assinalar que as artimanhas poéticas intervêm no processo de construção de saberes por meio da edificação de um espaço em que os símbolos, as estéticas e o protagonismo negros são valorizados. Forjam-se referências artísticas, intelectuais e políticas orientadas para a contestação dos marcos de exclusão impostos às periferias e aos negros, bem como para a produção de discursos e representações de forma endógena. A forma de organização dos recitais e demais atividades a eles vinculadas são embasados na necessidade de estabelecer para negros e periféricos um sentido de compreensão mútua, de continuidade e partilha, quilombos urbanos, pontos de resistência. 


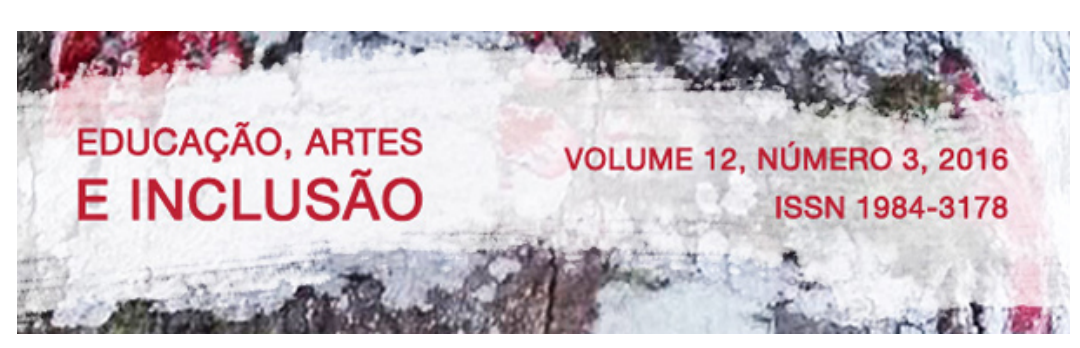

\section{REFERÊNCIAS}

ALVES, E. R. F. Outremização e revide de colonizado e colonizador em The narrative of jacobus coetzee (1974), de J. M. COETZEE. Maringá, PR, 2006, 192f. Dissertação (Mestradoem Letras) - Universidade Estadual de Maringá (UEM), 2006.

ANDRÉ, M. C. Processos de subjetivação em afro-brasileiros: Anotações para um estudo. Psicologia: Teoria e Pesquisa, v. 23, n. 2, p.159-168, 2007.

ANDREWS, G. R. Negros e brancos em São Paulo: (1888-1988). Bauru: Edusc, 1998.

ARRUDA, A. Teoria das representações sociais e teorias de gênero. Cadernos de Pesquisa, (117), p.127-147, 2002. Dispoível em: < https://dx.doi.org/10.1590/S0100-15742002000300007>, Acesso realizado em 16 de junho de 2016.

BENTO M. A. S.; CARONE, I. Psicologia Social do Racismo: Estudos sobre branqueamento e branquitude no Brasil (2a ed.). São Paulo: Vozes, 2002

BARRIOS, O. Del apartheid a la democracia: el teatro como resistencia y efecto curativo contra la violencia racial en Sudáfrica. En BARRIOS, O. (Ed.) Realidad y representación de la violencia.Salamanca: EdicionesUniversidad de Salamanca, p. 257-281, 2002.

BORGES, E.; MEDEIROS, C. A.; d'ADESKY, J. (orgs.) Racismo, preconceito e intolerância. São Paulo: Atual, 2002.

COTA, L. G. S. A “pujante mocidade": estudantes, professores e movimento abolicionista em ouro preto na última década da escravidão. Disponível em http://www.ichs.ufop.br/memorial/trab2/h545.pdf. Acesso realizado em 16 de junho de 2016.

DESCHAMPS, J. C. e MOLINER, P. A identidade em Psicologia Social: Dos Processos Identitários às Representações Sociais. Petróplis, RJ: Vozes, 2009, 198p.

FERREIRA, R. F. O brasileiro, o racismo silencioso e a emancipação do afro-descendente. Psicologia\&Sociedade; v.14, n.1, p. 69-86, 2002.

GOMES, N. L. Alguns termos e conceitos presentes no debate sobre relações raciais no Brasil: uma breve discussão. In: BRASIL. Ministério da Educação. Educação antirracista: caminhos abertos pela Lei Federal n. 10.639/03. Brasília: Ministério da Educação, Secretaria de Educação Continuada, Alfabetização e Diversidade, p. 39-62, 2005. GUIMARÃES, A. S. A. Racismo e anti-racismo no Brasil. Rio de Janeiro: Ed. 34, 1999. HALL, S. A identidade cultural na pós-modernidade. Trad. Tomáz Tadeu da Silva e Guacira Lopes Louro. Rio de Janeiro: DP \&A., 2005.

HASENBALG, C. Discriminação e desigualdades raciais no Brasil. Rio de Janeiro: Graal, 1979.

JODELET, D. A alteridade como produto e processo psicossocial. In: ARRUDA, A. (org.), Representando a alteridade. $2^{\mathrm{a}}$ edição. Petrópolis: Editora Vozes, 1998. 


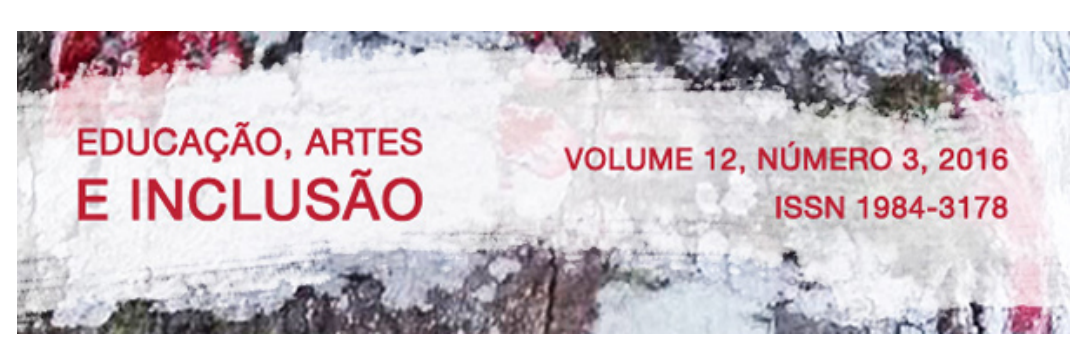

- Representações sociais: um domínio em expansão. In: JODELET, D. (org.). As Representações sociais. Rio de Janeiro: Eduerj, 2002.

KIRKWOOD, M. Literature and popular culture in South Africa. Third World Quarterly, v. 9, n. 2, p. 657-671, 1987.

LARLHAM, P. Black theater, dance and ritual in South Africa. Ann Arbor, Micghigan: UMI Research Publication, 1985.

MARINGONI, G. O destino dos negros após a abolição. Desafios do desenvolvimento. Ano 8, edição 70, 2011.

MARTÍN-BARÓ, I. O papel do psicólogo. Estudos de Psicologia, Natal, 2, 1, 7-27, 1996.

MOSCOVICI, S. A representação social da psicanálise. Rio de Janeiro: Zahar Editores, 1978.

MUNANGA, K. Negritude: Usos e sentidos. 2a. ed. São Paulo: Ática, 1988.

Negritude e identidade negra ou afrodescendente: um racismo ao avesso? Revista

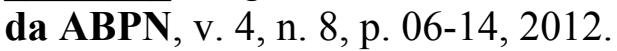

NASCIMENTO, E. P. A periferia de São Paulo: revendo discursos, atualizando o debate. Revista Rua; v. 2; n.6; 2010.

PÍCOLI, M. A. Ideias de liberdade na cena política capixaba: o movimento abolicionista em vitória(1869/1888). Vitória, ES, 2009, 143f. Dissertação (Mestrado em História Social) Universidade Federal do Espírito Santo, 2009.

SAMPSON, A. O negro e o ouro: magnatas, revolucionários e o apartheid. São Paulo: Companhia das letras, 1988.

SANT'ANNA, T. "Noites abolicionistas": As mulheres encenam o teatro e abusam Do piano na cidade de goiás (1870-1888). Opsis - Revista do NIESC, vol. 6, 2006.

SANTOS, B. S. Pela mão de Alice - O social e o político na pós-modernidade. Campinas: Cortez, 1996.

. A gramática do tempo: para uma nova cultura política. São Paulo: Cortez, 2008.

SANTOS, E. F. (2015) Das margens, escritos negros: Relações entre Literatura Periférica e identidade negra. São Carlos, SP, 2015, 247f. Tese (Doutorado em Psicologia) - Universidade Federal de São Carlos, 2015.

SILVA, M. A. M. Aproximações entre as ideias de literatura negra e periférica contemporâneas?Anais do III Simpósio de Pós-Graduandos em Sociologia, São Paulo, 2010. 


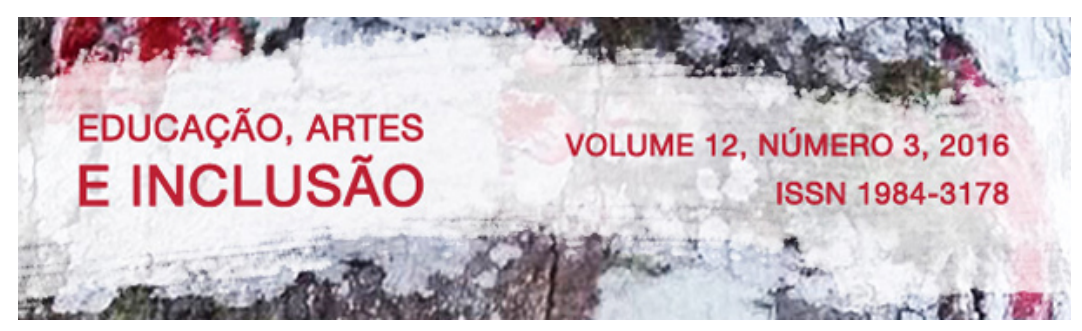

SILVA, M. A. M. A descoberta do insólito: literatura negra e literatura periférica no Brasil (1960-2000) Campinas, SP, 2011, 448f. Tese (Doutorado em Sociologia) - Universidade Estadual de Campinas, 2011.

SILVA, R. A periferia pede passagem: trajetória social e intelectual de Mano Brown. Campinas, SP, 2012, 302f. Tese (Doutorado em Sociologia) - Universidade Estadual de Campinas, 2012.

SKIDMORE, T. E. Preto no branco: raça e nacionalidade no pensamento brasileiro. Rio de Janeiro: Paz e Terra, 1976.

Recebido em 29 de junho de 2016 Aprovado em 28 de outubro de 2016 